\title{
The activation of the Sox2 RR2 pluripotency transcriptional reporter in human breast cancer cell lines is dynamic and labels cells with higher tumorigenic potential
}

\author{
Juan Manuel Iglesias 1,2, Olatz Leis ${ }^{1,3}$, Estíbaliz Pérez Ruiz ${ }^{1}$, Juan Gumuzio Barrie ${ }^{1,3}$, \\ Francisco Garcia-Garcia ${ }^{4,5}$, Ariane Aduriz ${ }^{1}$, Izaskun Beloqui ${ }^{1}$, Susana Hernandez-Garcia ${ }^{6}$, Maria Paz \\ Lopez-Mato ${ }^{1}$, Joaquin Dopazo ${ }^{4,5,7}$, Atanasio Pandiella ${ }^{6}$, Javier A. Menendez ${ }^{8,9}$ and Angel Garcia Martin ${ }^{1,3} *$
}

${ }^{1}$ Regulation of Cell Growth Laboratory, Fundacion Inbiomed, San Sebastian, Spain

2 Synpromics Ltd, Edinburgh, UK

${ }^{3}$ StemTek Therapeutics, Bilbao, Spain

${ }^{4}$ Computational Genomics Institute, Centro de Investigación Principe Felipe (CIPF), Valencia, Spain

${ }^{5}$ Functional Genomics Node, Centro de Investigación Principe Felipe (CIPF), Spanish National Institute of Bioinformatics (INB), Valencia, Spain

${ }^{6}$ Instituto de Biología Molecular y Celular del Cancer, Salamanca, Spain

${ }^{7}$ Centro de Investigación Biomédica en Red de Enfermedades Raras (CIBERER), Valencia, Spain

${ }^{8}$ Translational Research Laboratory, Catalan Institute of Oncology (ICO), Girona, Spain

${ }^{9}$ Girona Biomedical Research Institute (IDIBGi), Girona, Spain

\section{Edited by:}

Pilar Blancafort, The University of Western Australia, Australia

Reviewed by:

Deborah Stroka, University of Bern, Switzerland

Daniel Christian Hoessli, International Center for Chemical and Biological

Sciences, Switzerland

*Correspondence:

Angel Garcia Martin, StemTek

Therapeutics, Rodriguez Arias $233^{\circ}$

dpto. 2-3, Bilbao 48011, Spain

e-mail:agmartin@

stemtektherapeutics.com
The striking similarity displayed at the mechanistic level between tumorigenesis and the generation of induced pluripotent stem cells and the fact that genes and pathways relevant for embryonic development are reactivated during tumor progression highlights the link between pluripotency and cancer. Based on these observations, we tested whether it is possible to use a pluripotency-associated transcriptional reporter, whose activation is driven by the SRR2 enhancer from the Sox2 gene promoter (named S4+ reporter), to isolate cancer stem cells (CSCs) from breast cancer cell lines. The S4+ pluripotency transcriptional reporter allows the isolation of cells with enhanced tumorigenic potential and its activation was switched on and off in the cell lines studied, reflecting a plastic cellular process. Microarray analysis comparing the populations in which the reporter construct is active versus inactive showed that positive cells expressed higher mRNA levels of cytokines (IL8, IL-6, TNF) and genes (such as ATF3, SNAI2, and KLF6) previously related with the CSC phenotype in breast cancer.

Keywords: Sox2, breast cancer stem cell, pluripotency, reporter, EMT

\section{INTRODUCTION}

Cancer stem cells (CSCs) play a central role in tumor progression and recurrence, but our knowledge of their biology and origin is still limited. The lack of good CSC markers in solid tumors could explain our limited understanding of its biology and hampers the development of more efficient chemotherapy treatments. In breast cancer, fluorescent substrates (like Aldefluor), DNA dyes (such as Hoechst 33342 or Rhodamine 123 for the isolation of the side population) or different combinations of surface markers (CD24, CD44, CD133, CD49f, CD29, CD90, CD14) can be used to isolate little overlapping cell populations displaying enhanced tumor-initiating potential. To better understand the origin and dynamics of breast CSCs and to be able to use this knowledge to develop novel therapeutic approaches, new isolation methods and/or more specific combinations of markers are needed.

Cancer and developmental biology scientists realized over a century ago that genes and pathways relevant to cancer overlap with fetal development as reflected in the reactivation of embryonic genes during tumor progression. Consequently, the question was raised of whether tumors could arise from transformation of tissue stem cells or "retro-differentiation" of more differentiated cells (1). Nearly 40 years latter, these ideas and questions are still hot spots in cancer research. The "retro-differentiation" concept can be now translated as cellular plasticity, a process by which nonstem differentiated cells can spontaneously acquire stem cell-like characteristics (2). This phenomenon has important implications for cancer therapy and a big impact on our current view of the CSC hypothesis. The CSC model holds that tumors are organized in a cellular hierarchy in which CSCs are the only cells with unlimited proliferation potential and responsible for tumor growth and propagation. Originally, the CSC hypothesis was a linear model with the CSC on the top of the hierarchy and the more differentiated cells on the bottom, but the concept of cellular plasticity and experimental observations are challenging this model (3).

It is striking that the similarity observed at the mechanistic level between tumorigenesis and the generation of induced pluripotent stem (iPS) cells from fibroblasts as described by Takahashi and Yamanaka (4). The production of these iPS cells required the overexpression of four transcription factors, Oct4, Sox2, Klf4, and cMyc, although Klf4 and c-Myc can be replaced by Lin28 and Nanog (5) and may even be dispensable. The efficiency of this reprograming process is extremely low and remains so far an in vitro 
phenomenon since there is no evidence that it can naturally occur in vivo. The mechanisms underlying the reprogramming process are not well understood yet; however, the three main transcription factors Oct4, Sox2, and Nanog, called master regulators of pluripotency, have proved responsible for maintaining the undifferentiated state $(6,7)$. Recently, the processes of reprograming and tumorigenesis have been linked as the p53 tumor suppressor, one of the main regulators of oncogenic transformation, controls the induction of pluripotency (8-10).

Both processes, reprograming and transformation, need the expression or activation of oncogenes, inactivation of tumor suppressor genes, overriding the senescence and apoptotic barriers and both processes also involve epigenetic changes and a metabolic switch toward a glycolytic metabolism $(11,12)$. The work from Illmensee and Mintz (13) in the mid 70s strengthens the bonds between pluripotency and cancer. They demonstrated that teratocarcinoma cells are developmentally pluripotent since single teratocarcinoma cells injected into mouse blastocysts can differentiate into many developmentally unrelated tissues. In recent years, the work from Gill Smith's group has shown that breast CSCs are at least multipotent. Their work clearly shows that CSCs when placed in the right microenvironment can behave as phenotypically normal and can contribute to all cell types within the mammary gland epithelium $(14,15)$. Furthermore, it has been shown that breast CSCs have the ability to differentiate not only in epithelial but also in the endothelial lineage (16). This ability of CSCs to differentiate into unrelated cell types is also supported by the fact that glioblastoma stem/progenitor cells can differentiate into endothelial cells contributing to the vascularization of the tumor and hence to tumor progression (17).

Sox2 is a good example of a gene involved in embryonic development whose expression is reactivated during tumor generation, as Sox 2 is critical to maintain the pluripotent phenotype in embryonic stem cells (ESCs) (18) and its expression is reactivated during tumor progression (19-22). Furthermore, Sox2 is part of the original Yamanaka cocktail of transcription factors necessary to reprogram somatic adult cells into iPS cells. These observations, together with the lack of reliable surface markers to isolate breast CSCs, drove us to test whether a pluripotency transcriptional GFP reporter based on the SRR2 enhancer from the Sox2 gene, developed to isolate IPS cells (23), can be used to isolate cells with cancer stem-like properties from breast cancer cell lines (24, 25). Our results showed that the activation of this transcriptional GFP reporter in breast cancer cell lines is dynamic and identifies a subpopulation of cells with enhanced tumorigenic potential. Furthermore, when cultures depleted of GFP-positive cells were established and followed over time, some cells switched on the reporter and after a while GFP-negative and GFP-positive populations reached a steady state. Interestingly, the cells in which the reporter is active display higher mRNA levels of IL6, IL8, TNF, ATF3, KLF6, or SNAI2, genes previously related with the CSC-like phenotype and cellular plasticity in breast tumors.

\section{MATERIALS AND METHODS}

\section{CELL LINES AND CULTURE CONDITIONS}

MCF7 and MDA-MB-231 breast carcinoma cell lines were obtained directly from ATCC (Manasses, VA, USA) and were grown in DMEM (Gibco, Carlsbad, CA, USA) supplemented with $10 \%$ fetal bovine serum (Sigma, St. Louis, MO, USA) and 1\% Penicillin/Streptomycin (Sigma, St. Louis, MO, USA). MDA-MB436 cell line was a kind gift from T. Stein (University of Glasgow, UK, previously obtained from ATCC, Manassas, VA, USA) and was grown in DMEM (Gibco, Carlsbad, CA, USA) supplemented with $10 \%$ fetal bovine serum (Sigma, St. Louis, MO, USA), $20 \mathrm{ng} / \mathrm{ml}$ Insulin (Sigma, St. Louis, MO, USA) and 1\% penicillin/streptomycin (Sigma, St. Louis, MO, USA). All the cell lines were kept at $37^{\circ} \mathrm{C}$ in a $5 \% \mathrm{CO}_{2}$ incubator.

\section{MOUSE XENOGRAFT ASSAYS}

Female 6-week-old athymic nude mice (Balb/c $\mathrm{Nu} / \mathrm{Nu}$ ) were purchased from Charles River, and were housed in specifically designed pathogen-free isolation animal facility. All animal procedures were performed in accordance with institutional animal care and use guidelines and approved by the IRB. GFP High and $\mathrm{GFP}^{\text {Low }}$ MCF7 cells were resuspended in $200 \mu \mathrm{l}$ of PBS with matrigel and subcutaneously inoculated in left and right caudal mammary fat pads. In all, $2.5 \times 10^{6} ; 0.5 \times 10^{6}$, and $0.25 \times 10^{6}$ GFP High MCF7cells were inoculated in the right mammary fat pad, with their respective GFP ${ }^{\text {Low }}$ MCF7 controls in the left mammary fat pad. Mice were weighed and the inoculation sites were inspected by palpation at weekly intervals. When tumors become detectable manually, the growth rates were determined by weekly measurement of two diameters of the tumor with a Vernier caliper. The tumor volume was estimated as the volume of an ellipse using the following formula: $V=4 / 3 \times(a / 2) \times(b / 2) 2$, where " $a$ " and " $b$ " correspond to the longest and shortest diameter, respectively. Animals were euthanized when their tumors were harvested.

\section{FLOW CYTOMETRY AND MICROSCOPY}

Cells were harvested by trypsinization, trypsin was inactivated with regular medium, and DNAse I was added at a final concentration of $0.2 \mathrm{mg} / \mathrm{ml}$, cell suspensions were incubated at $37^{\circ} \mathrm{C}$ for another $10 \mathrm{~min}$ and spun down, and finally cell pellets were resuspended in a suitable volume of sorting buffer (PBS w/o Ca and Mg, 1\% BSA, 5 mM EDTA). TO-PRO-3 (Molecular Probes, Life Technologies) was added as dead cell indicator and BD FACSAria or BD FACSCanto machines were used for sorting and analysis experiments following the gating strategy depicted on the Figure S2 in Supplementary Material. When tracking the changes in the percentage of $\mathrm{GFP}^{\mathrm{High}}$ cells over time the FACSCanto was calibrated prior to the analysis using the Spherotech Rainbow beads (Spherotech Inc., Lake Forest, IL, USA) to ensure consistent signals over the course of the experiment and verify proper function of the machine.

\section{MICROARRAY ANALYSIS}

Total RNA from freshly sorted MCF7S4 $+\mathrm{GFP}^{\text {High }}$ and GFP ${ }^{\text {Low }}$ cells was prepared using TRIzol (Life Technologies) and whole genome gene expression analysis was performed using the HumanHT-12 v4 Expression BeadChip platform (Illumina) containing 47323 probes per chip. Data were standardized using background correction and quantile normalization (26). Differential gene expression was carried out using the limma (27) package from Biocondui (http://www.bioconductor.org/). We performed a statistical test for each probe according to Benjamini and 
Hochberg (28) methodology. Gene set analysis was carried out for the Gene Ontology terms using FatiScan (29) in Babelomics (30) (http://babelomics.bioinfo.cipf.es/). This is a web-based program for the functional interpretation of large-scale experiments. The test aims to directly test the behavior of blocks of functionally related genes, instead of focusing on single genes. This tool detects significantly up- or downregulated blocks of functionally related genes in lists of genes ordered by differential expression. FatiScan returns adjusted $p$-values based on false discovery rate (FDR) method (28, 31). Significant GO terms were represented by directed acyclic graphs from Blast2GO (32). GO annotation for the genes in the microarray where taken from Ensembl 56 release (http://www.ensembl.org).

\section{LENTIVIRAL GENE TRANSFER}

Lentiviral particles encoding the pluripotency transcriptional reporter pL-SIN-EOS-S(4+) EGFP (23) were produced in-house at the Viral Vectors Core Unit. Cell lines were plated the day before the infection in six-well plates at a cell density of $0.25 \times 10^{6}$ cells per well and exposed to the lentiviral particles at a MOI 2.5 in serum free medium for $6 \mathrm{~h}$, cells were washed twice with serum free medium and kept in regular medium thereafter.

\section{RESULTS}

THE S4+ TRANSCRIPTIONAL REPORTER IS ACTIVE IN BREAST CANCER CELL LINES

The pL-SIN-EOS-S(4+) EGFP pluripotency transcriptional reporter (from now on $\mathrm{S} 4+$ reporter) was described by Hotta et al. (23) as a tool to isolate human iPS cells. The backbone of this reporter is based on the EOS lentiviral system and the synthetic promoter controlling the expression of the EGFP reporter is made of a minimal promoter sequence derived from the LTR promoter from an early transposon (ETn) and four tandem repeats of the SRR2 enhancer sequence from the Sox 2 gene (Figure S1 in Supplementary Material). To test whether this pluripotency reporter is active in breast cancer cell lines, cell lines MCF-7S4+ (representing the most common luminal breast cancer type), MDA-MB-231S4+ (as example of mesenchymal-like breast carcinoma), and MDAMB-436S4+ (representing BRCA1 deficient breast cancer) were generated from parental cell lines through lentiviral gene transfer of the pL-SIN-EOS-S(4+) EGFP transcriptional reporter. The activation of the transcriptional reporter was analyzed by fluorescence microscopy to detect GFP expression. The three $\mathrm{S} 4+$ derivative cell lines expressed different levels of GFP in individual cells as shown in Figure 1. To quantify the number of cells expressing GFP and its expression levels, FACS analysis was performed. As shown in Figure 1, most of the GFP-positive cells expressed low levels of GFP with just a few cells expressing high levels of GFP in the three cell lines.

\section{CELLS IN WHICH S4+ REPORTER IS ACTIVE ARE MORE TUMORIGENIC}

One of the first questions we made after we found out that the $\mathrm{S} 4+$ reporter is active in a small population of cells was if there is any difference in tumorigenic potential between the GFP + and GFP- cells. Before we could address this question, we performed a calibration experiment to find out the minimum GFP levels detected on the FACS machine that can be detected by the naked eye on the microscope to help us decide which populations to select for the assay. MCF7S4+ cells were used to establish regions of fluorescence intensity (termed P2-P11) so cells falling in gates P10, P11, and P3 were GFP fluorescent when examined under the fluorescent microscope, as shown in Figure S2 in Supplementary Material, thus we decided to use cells in gate P3 as GFPHigh for further studies. We decided to select the gate P4 as GFP ${ }^{\mathrm{Low}}$ and not one of the gates on its right because in the latter ones there is a potential mixture of cells in which the reporter is inactive and cells lacking any viral integration. As control, expression of Sox2 was checked through RT-PCR, showing increased expression of Sox2 in $\mathrm{GFP}^{\text {High }}$ cells compared to GFP ${ }^{\text {Low }}$ cells, as expected.

On the basis of these results, we tested if there is any difference in tumorigenic potential between $\mathrm{GFP}^{\mathrm{High}}$ and $\mathrm{GFP}^{\mathrm{Low}}$ cells in the MCF7S4+ cell line. GFP ${ }^{\text {High }}$ and GFP ${ }^{\text {Low }}$ populations were then FACS sorted, injected subcutaneously in each flank of nude female mice, and tumor growth was monitored for 8 weeks. As shown in Figure 2, tumors coming from $\mathrm{GFP}^{\mathrm{High}}$ cells grew out first and faster than tumors initiated by GFP ${ }^{\text {Low }}$ cells, and this difference is more evident when higher numbers of cells are injected. We used MCF7S4+ cells as model for tumorigenesis in xenograft experiments instead of a mesenchymal-like model of breast cancer (such as MDA-MB-231S4+) because mesenchymal-like breast carcinoma cells are very invasive and spread rapidly when xenografted to immunocompromised mice, making this model unfeasible to compare direct tumorigenicity.

\section{THE S4+ TRANSCRIPTIONAL REPORTER IS DYNAMIC IN BREAST CANCER CELL LINES}

Hotta et al. have shown that the $\mathrm{S} 4+$ reporter is dynamic; it is off in non-pluripotent cells, such as fibroblasts, turns on in iPS cells, and turns off again when the iPS cells are induced to differentiate into any lineage. To test whether the reporter is also dynamic in breast cancer cell lines, GFP ${ }^{\text {High }}$ and GFP ${ }^{\text {Low }}$ populations where sorted, placed in culture and changes in fluorescence where monitored by FACS analysis at each passage. When GFP ${ }^{\text {Low }}$ cells are placed in culture, the heterogeneity of the parental cell line is restored after just few days in culture (Figure 3), the same is true for the GFPHigh population. The $\mathrm{S} 4+$ transcriptional reporter is also dynamic in MDA-MB-231 and MDA-MB-436 breast carcinoma cell lines, as shown in Figure S3 in Supplementary Material.

To confirm that the transcriptional reporters are dynamic and the restoration of the heterogeneity observed in the original cell line is not due to contamination during the sorting process, a clonogenic assay was set up using the MCF7 S4+ cell line. To carry on this assay, individual GFP ${ }^{\text {High }}$ or GFP ${ }^{\text {Low }}$ cells were FACS sorted into each well of a 96-well plate, each well was checked for the presence of an individual cell at the microscope, and after 3 weeks, the colonies were scored for the presence of mixed-colonies with $\mathrm{GFP}^{+}$or $\mathrm{GFP}^{-}$cells by fluorescence microscopy (experimental outline depicted in Figure S4 in Supplementary Material). This assay shows that the frequency of firing is much lower than the frequency of extinction of GFP as it would be expected if GFP labels CSCs and the dynamic activity of the transcriptional reporter reflects cellular plasticity (Table 1).

In these series of experiments, we observed that when MCF7S4+ GFP Low cells are placed in culture they switch on 
A

MDA-MB-231 S4+
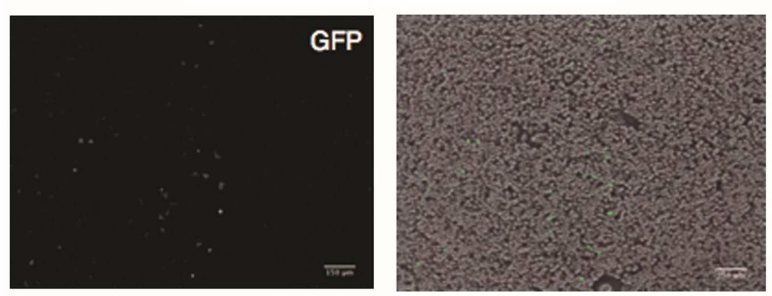

MDA-MB-436 S4+
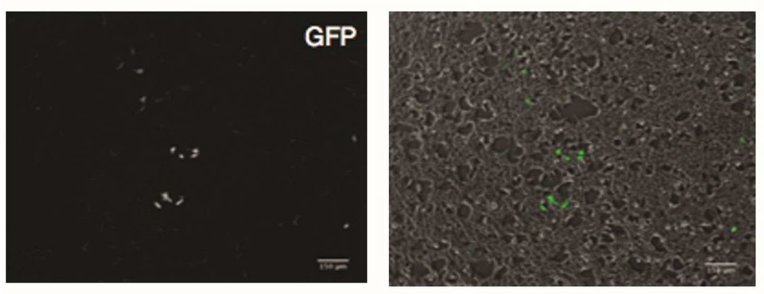

\section{MCF7 S4 ${ }^{+}$}
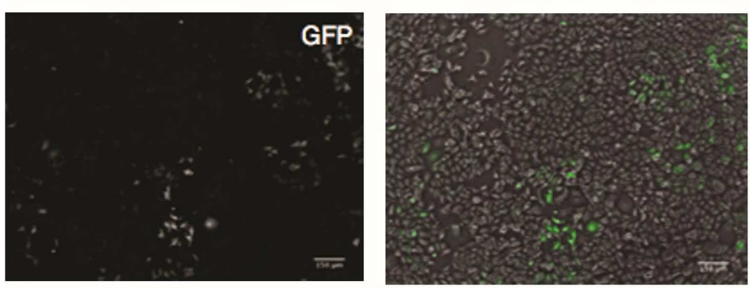

FIGURE 1 | S4+ pluripotency transcriptional reporter is active in breast cancer cell lines. (A) On the left, fluorescence images of MDA-MB-231, MDA-MB-436, and MCF7 cell lines infected with the S4+ reporter to detect GFP expression. On the right are shown the fluorescence image (in green) merge with the bright-field image. (B) FACS plots of the wild-type cell lines
B

B $\quad$ WT

$\mathrm{S4}^{+}$
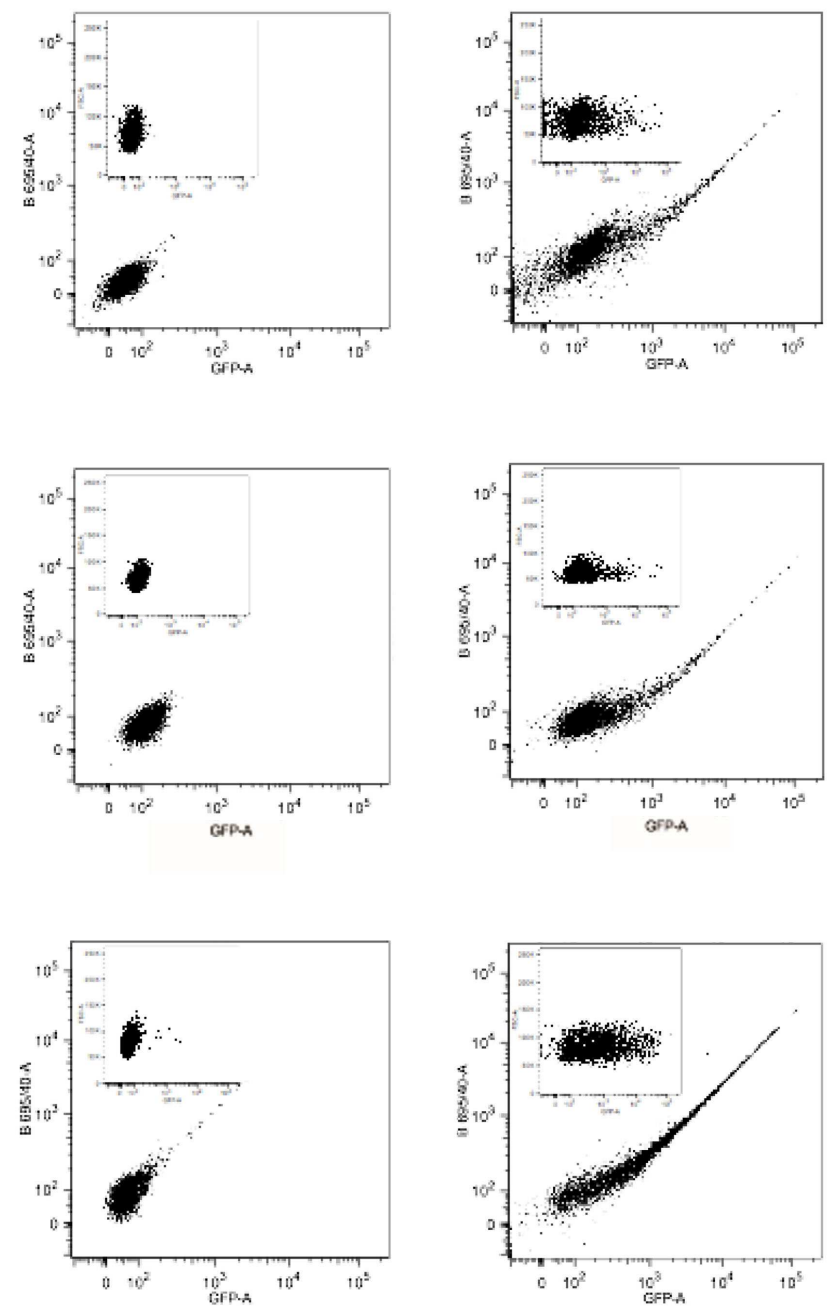

MDA-MB-231, MDA-MB-436, and MCF7 and the S4+ derivatives infected with the S4+ reporter. On the bigger plot, GFP fluorescence is displayed on the $X$-axis and the fluorescence collected through the 695/40 filter on the $Y$-axis. On the inset, GFP fluorescence is displayed on the $X$-axis and the forward scattering on the $Y$-axis. the $\mathrm{S} 4+$ reporter, and after a few passages, the culture reached a steady state in which the percentage of $\mathrm{GFP}^{\mathrm{High}}$ cells stays around $0.1-0.3 \%$.

\section{IDENTIFICATION OF GENES DIFFERENTIALLY EXPRESSED AMONG GFPHIGH AND GFPLOW POPULATIONS}

$\mathrm{GFP}^{\text {High }}$ and GFPLow populations from the MCF7S4+ cell line were isolated by FACS and total RNA was prepared to perform microarray analysis on the Illumina HumanHT-12_V4 BeadChip platform. Results were normalized and analyzed using Bioconductor and Babelomics, showing that 42 genes were found differentially expressed between the two populations with an adj. $p$-value $<0.1$, with 40 of those genes showing higher expression in the GFP ${ }^{\text {High }}$ population (Figure 4). Among the genes upregulated in $\mathrm{GFP}^{\text {High }}$ cells are cytokines (IL-6, IL-8, or TNF) and transcription factors (KLF6, ATF3, SNAI2) that have been previously related with cancer stemness, cellular plasticity, or both. GO analysis showed enrichment in genes related to anti-apoptosis (GO:0006916) and positive regulation of nitric oxide biosynthetic process (GO:0045429) among others (Figure 4). Interestingly, increased nitric oxide synthase expression in estrogen receptor-negative breast cancer patients predicts poor survival (33) and the enrichment in anti-apoptotic genes can contribute the intrinsic chemoresistance characteristic of BCSCs (34). Further experimentation will be needed to validate the links between these processes, specially inflammation, and CSC induction. 
A
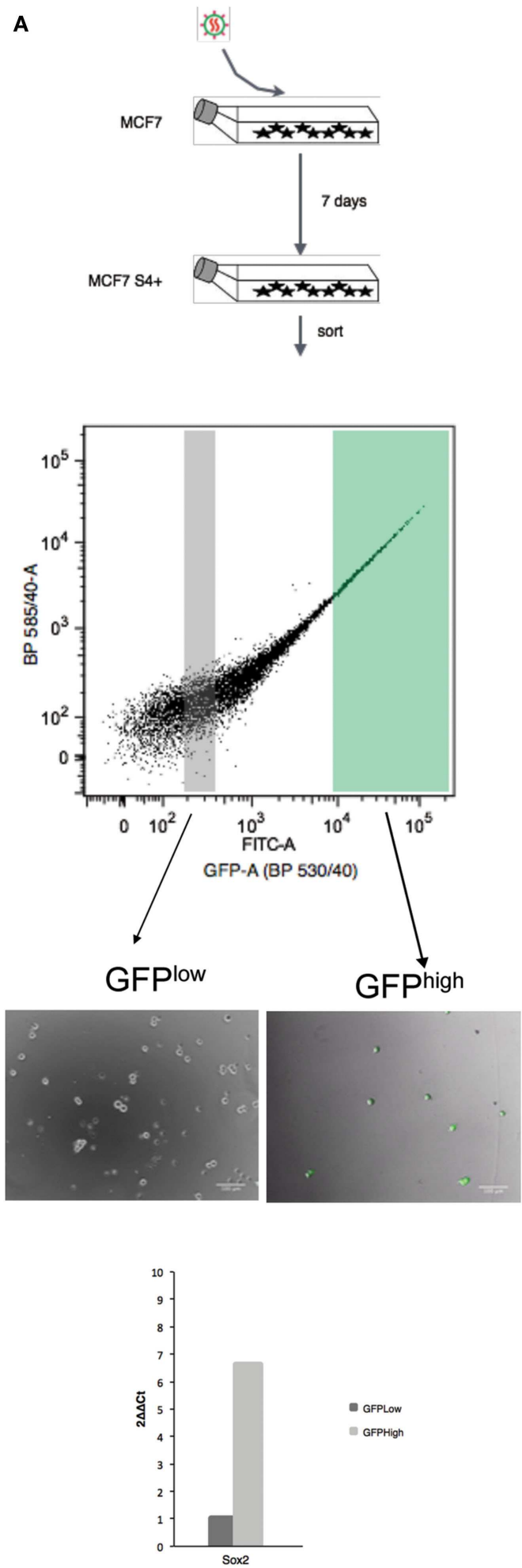

FIGURE 2 | Cells in which the S4+ reporter is active show higher tumorigenic potential in NOD/SCID mice. The outline of the experiment is shown on the left (A) and the outcome on the right (B). (A) MCF7 cells were infected with the lentiviral reporter vector, 7 days later GFPHigh and GFPLow populations were sorted, GFP expression verified by fluorescent microscopy
B
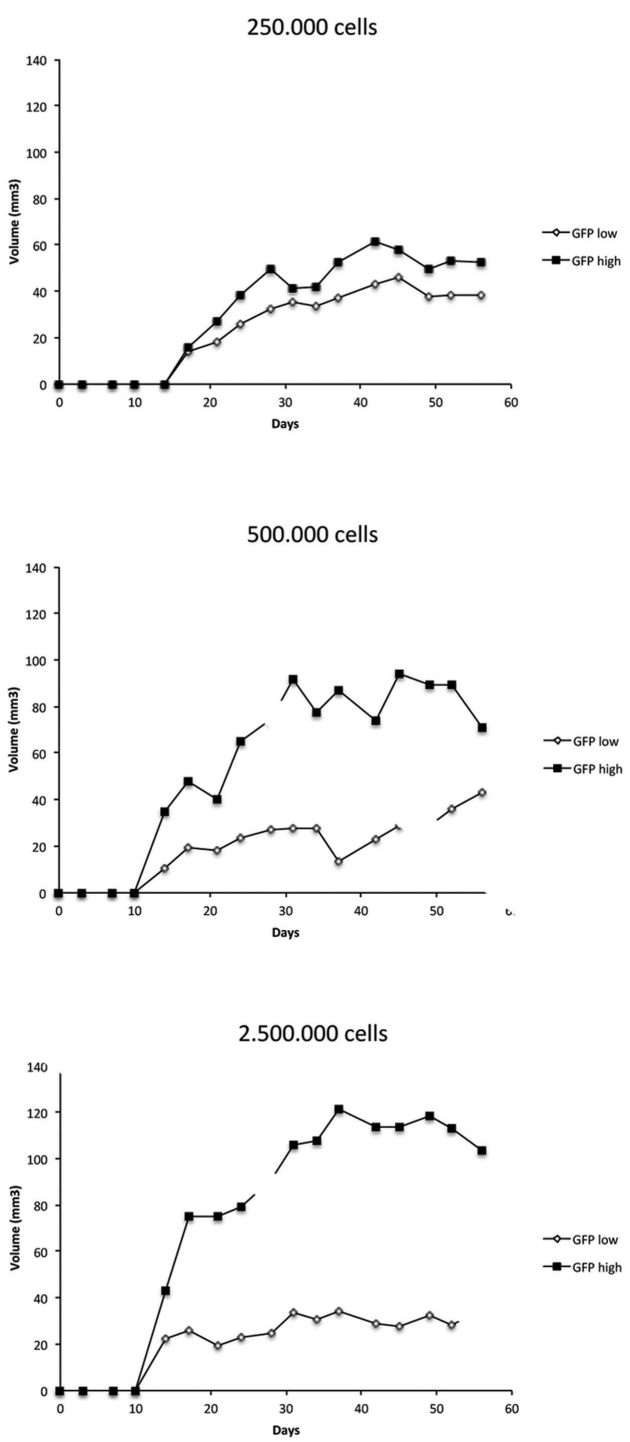

and SOX2 mRNA differential expression assessed by qPCR. (B) The GFPHigh and GFPLow cells were culture for 2 days and subcutaneously injected into the left (GFPLow) or right (GFPHigh) fat pads of 6-week-old female nude mice and tumor growth was monitored weekly. In these experiments, three animals per condition were used and the standard deviation is plotted for each time point. 


\section{A}
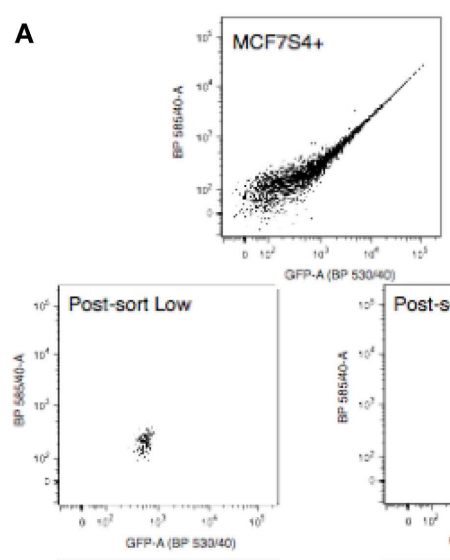

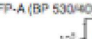
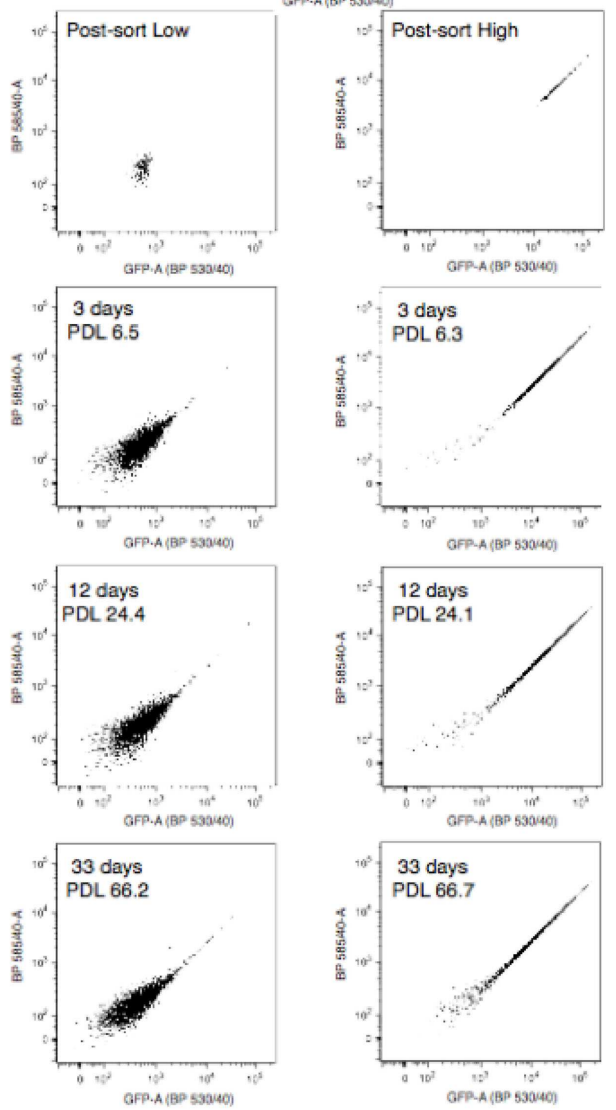

FIGURE 3 |The S4+ reporter is dynamic in MCF7 cells. (A) FACS plots of the parental MCF7S4+ cell line, the GFPHigh and GFPLow populations just after sorting, and after 3,12 , and 33 days in culture. (B) Typical micrographs of cell cultures at indicated time points. The

Table 1 | Frequency of reporter activation and inactivation through single cell plating.

\begin{tabular}{llll}
\hline & Number of positions & GFPlow & GFPhigh \\
\hline Day 1 & Analyzed & 288 & 288 \\
& Containing 1 cell & 212 & 256 \\
\multirow{2}{*}{ After 3 weeks } & With colonies & $98(46.2 \%)$ & $144(56.2 \%)$ \\
& With colonies made of & $9(9.1 \%)$ & $76(52.7 \%)$ \\
& GFP+ and GFP- cells & & \\
\hline
\end{tabular}

\section{DISCUSSION}

Different combinations of surface markers have been described to isolate CSCs, but it is striking that little overlap has been found

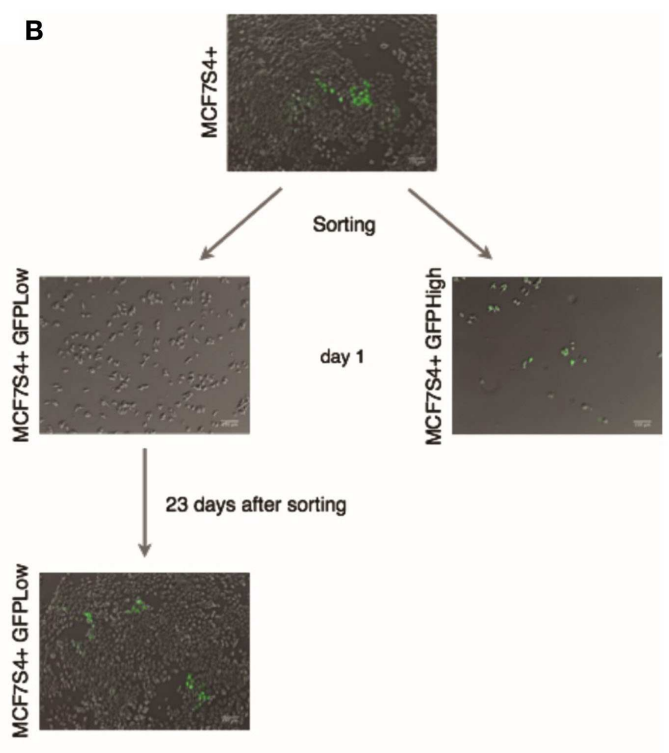

GFPHigh and GFP Low populations were cultured on its own and changes in fluorescence were monitored by FACS at the indicated time points. Population doublings after sorting are also indicated for each time point.

between CSC markers reported in different tumor types (35). Prominin (CD133) is a good marker for brain and colon CSCs, but has never been successfully used for isolating breast CSCs. Even within breast tumors, the accepted combination of surface markers CD44/CD24 shows differences among different subtypes, being the CD44+/CD24- phenotype common in the basal subtype, specially in BRCA1 hereditary tumors, but surprisingly scarce in HER2-positive tumors (36). In this work, we utilize transcription programs unique in stem cells as a new method to report the activity of CSCs.

The work from Illmensee and Mintz (13) linked teratocarcinoma cells to pluripotency. Regulatory networks orchestrated by key transcription factors like SOX2, OCT4, and NANOG have been proposed to play an important role maintaining ESC identity $(6,7)$. Interestingly, mRNA profiling studies suggest that ESC and 


\begin{tabular}{|c|c|c|c|c|c|c|}
\hline Aerm & Term size & $\begin{array}{c}\text { Term size } \\
\text { (in genome) }\end{array}$ & $\begin{array}{c}\text { Term annotation } \\
\% \text { per list }\end{array}$ & $\begin{array}{c}\text { Odds ratio } \\
\text { (loge) }\end{array}$ & p-value & Adjusted p-value \\
\hline $\begin{array}{c}\text { negative regulation of peptidase } \\
\text { activity (GO:0010466) }\end{array}$ & 21 & 21 & $\begin{array}{l}\text { list 1: } 8.82 \% \\
\text { list 2: } 0.08 \%\end{array}$ & 4,84 & 0,000003561 & 0,002677 \\
\hline $\begin{array}{c}\text { negative regulation of caspase } \\
\text { activity (GO:0043154) }\end{array}$ & 18 & 18 & $\begin{array}{l}\text { list 1: } 8.82 \% \\
\text { list 2: } 0.06 \%\end{array}$ & 5,02 & 0,000002192 & 0,002677 \\
\hline $\begin{array}{c}\text { positive regulation of nitric oxide } \\
\text { biosynthetic process (GO:0045429) }\end{array}$ & 22 & 28 & $\begin{array}{l}\text { list 1: } 8.82 \% \\
\text { list 2: } 0.08 \%\end{array}$ & 4,78 & 0,00000412 & 0,002677 \\
\hline $\begin{array}{c}\text { ER-nuclear signalling pathway } \\
\text { (GO:0006984) }\end{array}$ & 32 & 32 & $\begin{array}{l}\text { list 1: } 8.82 \% \\
\text { list 2: } 0.12 \%\end{array}$ & 4,36 & 0,00001314 & 0,00426 \\
\hline $\begin{array}{c}\text { response to endoplasmic reticulum } \\
\text { stress (GO:0034976) }\end{array}$ & 34 & 34 & $\begin{array}{l}\text { list 1: } 8.82 \% \\
\text { list 2: } 0.13 \%\end{array}$ & 4,2976 & 0,00001582 & 0,004616 \\
\hline $\begin{array}{c}\text { cellular response to stimulus } \\
\text { (GO:0051716) }\end{array}$ & 867 & 873 & $\begin{array}{l}\text { list 1: } 23.53 \% \\
\text { list 2: } 3.64 \%\end{array}$ & 2,09 & 0,00002479 & 0,006577 \\
\hline $\begin{array}{c}\text { cell cycle (GO:0007049) } \\
\text { anti-apoptosis (GO:0006916) }\end{array}$ & 246 & 252 & $\begin{array}{l}\text { list 1: } 11.76 \% \\
\text { list 2: } 1.03 \%\end{array}$ & 2,55 & 0,0004166 & 0,02763 \\
\hline $\begin{array}{c}\text { positive regulation of MAPK activity } \\
\text { (GO:0043406) }\end{array}$ & 108 & 114 & $\begin{array}{l}\text { list 1: } 8.82 \% \\
\text { list 2: } 0.45 \%\end{array}$ & 3,07 & 0,0005019 & 0,02888 \\
\hline
\end{tabular}

B
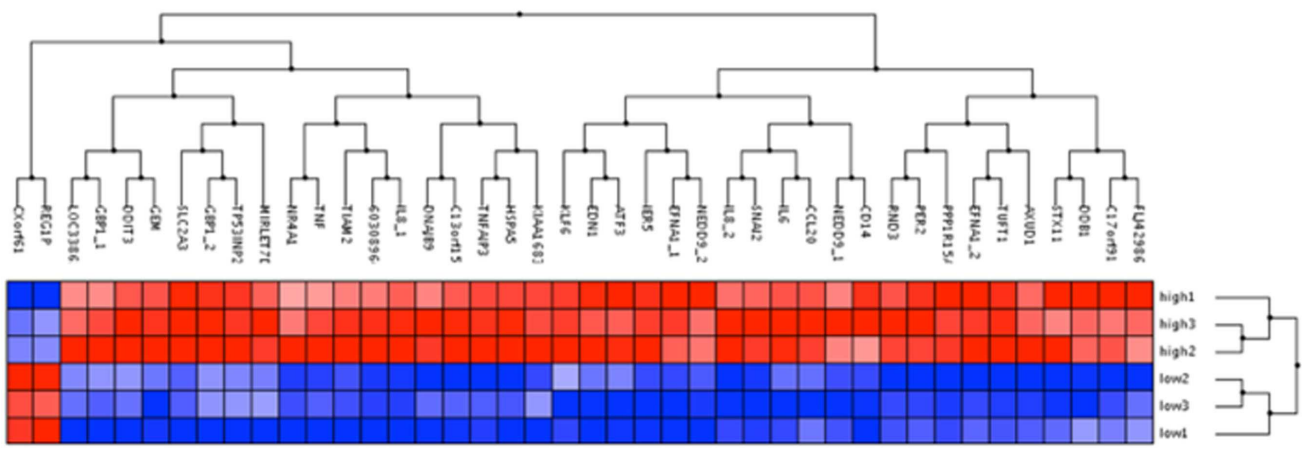

FIGURE 4 | Microarray profiling of GFPHigh versus GFPLow MCF7 cells. (A) GO terms enriched in the GFPHigh population identified by FatiScan enrichment analysis. (B) Genes (columns) differentially expressed between GFPHigh and GFPLow cells (rows). Red color denotes high expression, blue low expression.

CSCs share common transcriptional programs (37). Furthermore, transcriptional reporters containing regulatory regions derived from those genes had previously been successfully used to isolate CSCs (38-40). These observations and the striking similarity observed at the mechanistic level between tumorigenesis and the generation of iPS cells prompted us to test whether a pluripotency transcriptional reporter developed to isolate human iPS cells could be also used in the isolation of CSCs. The pluripotency transcriptional reporter selected to test our hypothesis was the pL-SIN-EOS-S(4+) EGFP (in short, S4+ reporter) (23). The synthetic promoter driving the expression of GFP is made of four tandem repeats of the SRR2 enhancer from the Sox2 gene plus the LTR from the mouse ETn. These transposons are only active during early mouse embryogenesis in ESCs and embryonic carcinoma (EC) cells. This configuration using a minimal promoter only active in ESCs and ECs and an enhancer sequence derived from the regulatory region of one of the key transcription factor for the maintenance of the ESC identity may provide a more specific way of isolating CSCs and may allow the isolation of CSCs from different tumor sources. Previous work from our laboratory
(19) and others $(41,42)$ had shown that Sox2 gene is activated in the early phases of breast tumor development and necessary for tumorigenicity of MCF7 cells; therefore, a reporter based on Sox2 promoter elements seemed appropriate.

After breast cancer cell lines are infected with the S4+ lentiviral transcriptional reporter, only a small fraction of cells switched on the expression of the GFP repoter, when inspected under the fluorescence microscope $\left(\mathrm{GFP}^{\mathrm{High}}\right)$. Interestingly, the $\mathrm{GFP}^{\mathrm{High}}$ cells showed enhanced tumorigenicity when injected into immunocompromised female mice.

The S4+ pluripotency transcriptional reporter is active in iPS and ES cells, but it is turned off when iPS cells are induced to differentiate (23). Here, we show for the first time that this reporter is also dynamic in breast cancer cell lines, as cell cultures depleted of $\mathrm{GFP}^{\mathrm{High}}$ cells show spontaneous conversion of $\mathrm{GFP}^{\mathrm{Low}}$ cells (these are the cells GFP-negative at the microscope, but with background GFP expression - measured through flow cytometry, demonstrating effective viral integration but not transcriptional activation of the reporter) into GFP High and after a few passages the culture reached a steady state, similar to the parental culture. This 
phenomenon is reminiscent of cellular plasticity as described by Chaffer et al. (2), as the spontaneous conversion to a stem-like state of non-stem cells. The reverse is also true, when $\mathrm{S} 4+$ cell lines were depleted of GFP ${ }^{\text {Low }}$ cells, some GFP High cells switched off the expression of the reporter becoming GFP ${ }^{\text {Low }}$, this might be equivalent to a differentiation process. In the breast cancer cell lines tested, the percentage of cells in which the reporter is active, ranges between 0.4 and $8 \%$ after transduction, this percentage fell below $1 \%$ when GFP ${ }^{\text {Low }}$ cultures were established and allowed to reach its steady state. These discrepancies in the percentage of fluorescent cells may be due to differences in the transduction efficiency and non-specific activation of the reporter due to positional effects after the lentiviral integration in the genome. Working with steady-state cultures derived from $\mathrm{GFP}^{\mathrm{Low}}$ cells reduces the unspecific activation of the reporter due to positional effects. We used cell lines representing the main subtypes of breast cancer to prevent cell line bias: MCF7 as luminal ER-dependent breast cancer, MDA-MB-231 as mesenchymal-like basal breast carcinoma, and MDA-MB-436 as a model of hereditary BRCA1-deficient breast cancer. Similar results were obtained from all cell lines. Expression of the reporter gene did not alter phenotypic features of the cell lines used, such as ER expression in MCF7 cells (data not shown). Moreover, we recently published (43) a link between E2/ERa signaling in breast cancer and pluripotency-like reporgramming, pointing to a mechanism where SOX2 can promote non-genomic E2 signaling that leads to nuclear phospho-Ser118ERa, which exacerbates genomic ER signaling in response to E2. Since E2 stimulation has been recently shown to enhance breast tumor-initiating cell survival (through downregulation of miR140), which targets SOX2, this suggests a bidirectional cross-talk interaction to regulate breast cancer activity.

In order to understand the mechanisms governing the interconversion of reporter positive and negative cells, transcriptional profiling was carried out. Comparison of $\mathrm{GFP}^{\text {High }}$ versus $\mathrm{GFP}^{\mathrm{Low}}$ populations showed many genes previously related with CSC homeostasis upregulated in the GFP High population, where the reporter is active. The cytokines IL- 6 and IL- 8 are among the upregulated genes in GFPHigh cells. IL- 6 secretion has been reported to modulate the inducible formation of breast CSCs and their dynamic equilibrium with non-stem cancer cells (44) and recombinant IL- 8 increased mammosphere formation and the ALDEFLUOR-positive population in breast cancer cell lines (25). The transcription factor ATF3 acts as an oncogene in mouse mammary gland (45) and enhances TGF $\beta$ signaling and CSC features in breast cancer cell lines (46). We found also genes related with epithelial-to-mesenchymal transition (EMT) upregulated in the GFPHigh population, such as SLUG or NEDD9. Recent studies suggest a link between EMT and acquisition of stem cell properties $(47,48)$ where Slug co-operates with a Sox family member (Sox9) in the reprogramming of differentiated luminal epithelial cells to a stem-like state in the mouse mammary gland and co-expression of both transcription factors in breast cancer is associated with patient survival (49). NEDD9 acts as a positive regulator of EMT in breast cancer cell lines (50), and it is also involved in mammary gland tumorigenesis $(51,52)$.

These data are compatible with a model of inducible formation of CSCs and their dynamic equilibrium with non-stem cancer cells. Further experimentation is needed to fully understand the molecular determinants controlling this process, which may have significant impact in our understanding of tumor generation and progression, and therefore opening new possibilities for therapeutic intervention. In this work, we demonstrate the use of a pluripotency related promoter as a tool to track CSC phenotype acquisition in breast cancer, suitable for novel drug discovery targeting the CSC compartment.

\section{ACKNOWLEDGMENTS}

This work is supported by grants from Obra Social Kutxa, Gobierno Vasco (Saiotek program and Consejería de Educación PI2010-25), and Instituto de Salud Carlos III Acción Estratégica en Salud (PI2010-01035). Work in Atanasio Pandiella lab is supported by the MINECO (BFU2012-39151).

\section{SUPPLEMENTARY MATERIAL}

The Supplementary Material for this article can be found online at http://www.frontiersin.org/Journal/10.3389/fonc.2014. 00308/abstract

\section{REFERENCES}

1. Uriel J. Cancer, retrodifferentiation, and the myth of Faust. Cancer Res (1976) 36:4269-75.

2. Chaffer CL, Brueckmann I, Scheel C, Kaestli AJ, Wiggins PA, Rodrigues LO, et al. Normal and neoplastic nonstem cells can spontaneously convert to a stem-like state. Proc Natl Acad Sci US A (2011) 108:7950-5. doi:10.1073/pnas.1102454108

3. Vermeulen L, de Sousa e Melo F, Richel DJ, Medema JP. The developing cancer stem-cell model: clinical challenges and opportunities. Lancet Oncol (2012) 13:e83-9. doi:10.1016/S1470-2045(11)70257-1

4. Takahashi K, Yamanaka S. Induction of pluripotent stem cells from mouse embryonic and adult fibroblast cultures by defined factors. Cell (2006) 126:663-76. doi:10.1016/j.cell.2006.07.024

5. Yu J, Vodyanik MA, Smuga-Otto K, Antosiewicz-Bourget J, Frane JL, Tian S, et al. Induced pluripotent stem cell lines derived from human somatic cells. Science (2007) 318:1917-20. doi:10.1126/science.1151526

6. Whyte WA, Orlando DA, Hnisz D, Abraham BJ, Lin CY, Kagey MH, et al. Master transcription factors and mediator establish super-enhancers at key cell identity genes. Cell (2013) 153:307-19. doi:10.1016/j.cell.2013.03.035

7. Thomson M, Liu SJ, Zou L-N, Smith Z, Meissner A, Ramanathan S. Pluripotency factors in embryonic stem cells regulate differentiation into germ layers. Cell (2011) 145:875-89. doi:10.1016/j.cell.2011.05.017

8. Kawamura T, Suzuki J, Wang YV, Menendez S, Morera LB, Raya A, et al. Linking the p53 tumour suppressor pathway to somatic cell reprogramming. Nature (2009) 460:1140-4. doi:10.1038/nature08311

9. Hong H, Takahashi K, Ichisaka T, Aoi T, Kanagawa O, Nakagawa M, et al. Suppression of induced pluripotent stem cell generation by the p53-p21 pathway. Nature (2009) 460:1132-5. doi:10.1038/nature08235

10. Tapia N, Schöler HR. p53 connects tumorigenesis and reprogramming to pluripotency. J Exp Med (2010) 207:2045-8. doi:10.1084/jem.20101866

11. Vazquez-Martin A, Vellon L, Quirós PM, Cufí S, de Galarreta E, Oliveras-Ferraros $\mathrm{C}$, et al. Activation of AMP-activated protein kinase (AMPK) provides a metabolic barrier to reprogramming somatic cells into stem cells. Cell Cycle (2012) 11:974-89. doi:10.4161/cc.11.5.19450

12. Riggs JW, Barrilleaux BL, Varlakhanova N, Bush KM, Chan V, Knoepfler PS. Induced pluripotency and oncogenic transformation are related processes. Stem Cells Dev (2013) 22:37-50. doi:10.1089/scd.2012.0375

13. Illmensee K, Mintz B. Totipotency and normal differentiation of single teratocarcinoma cells cloned by injection into blastocysts. Proc Natl Acad Sci U S A (1976) 73:549-53. doi:10.1073/pnas.73.2.549

14. Bussard KM, Smith GH. Human breast cancer cells are redirected to mammary epithelial cells upon interaction with the regenerating mammary gland microenvironment in-vivo. PLoS One (2012) 7:e49221. doi:10.1371/journal. pone.0049221 
15. Booth BW, Boulanger CA, Anderson LH, Smith GH. The normal mammary microenvironment suppresses the tumorigenic phenotype of mouse mammary tumor virus-neu-transformed mammary tumor cells. Oncogene (2011) 30:679-89. doi:10.1038/onc.2010.439

16. Bussolati B, Grange C, Sapino A, Camussi G. Endothelial cell differentiation of human breast tumour stem/progenitor cells. J Cell Mol Med (2009) 13:309-19. doi:10.1111/j.1582-4934.2008.00338.x

17. Pezzolo A, Parodi F, Marimpietri D, Raffaghello L, Cocco C, Pistorio A, et al. Oct-4+/Tenascin C+ neuroblastoma cells serve as progenitors of tumor-derived endothelial cells. Cell Res (2011) 21:1470-86. doi:10.1038/cr.2011.38

18. Fong H, Hohenstein KA, Donovan PJ. Regulation of self-renewal and pluripotency by Sox2 in human embryonic stem cells. Stem Cells (2008) 26:1931-8. doi:10.1634/stemcells.2007-1002

19. Leis O, Eguiara A, Lopez-Arribillaga E, Alberdi MJ, Hernandez-Garcia S, Elorriaga $\mathrm{K}$, et al. Sox 2 expression in breast tumours and activation in breast cancer stem cells. Oncogene (2012) 31:1354-65. doi:10.1038/onc.2011.338

20. Boumahdi S, Driessens G, Lapouge G, Rorive S, Nassar D, Le Mercier M, et al. SOX2 controls tumour initiation and cancer stem-cell functions in squamouscell carcinoma. Nature (2014) 511:246-50. doi:10.1038/nature13305

21. Vanner RJ, Remke M, Gallo M, Selvadurai HJ, Coutinho F, Lee L, et al. Quiescent Sox $2(+)$ cells drive hierarchical growth and relapse in sonic hedgehog subgroup medulloblastoma. Cancer Cell (2014) 26:33-47. doi:10.1016/j.ccr. 2014.05.005

22. Tam WL, Ng HH. Sox2: masterminding the root of cancer. Cancer Cell (2014) 26:3-5. doi:10.1016/j.ccr.2014.06.024

23. Hotta A, Cheung AYL, Farra N, Vijayaragavan K, Séguin CA, Draper JS, et al. Isolation of human iPS cells using EOS lentiviral vectors to select for pluripotency. Nat Methods (2009) 6:370-6. doi:10.1038/nmeth.1325

24. Fillmore CM, Kuperwasser C. Human breast cancer cell lines contain stem-like cells that self-renew, give rise to phenotypically diverse progeny and survive chemotherapy. Breast Cancer Res (2008) 10:R25. doi:10.1186/bcr1982

25. Charafe-Jauffret E, Ginestier C, Iovino F, Wicinski J, Cervera N, Finetti P, et al. Breast cancer cell lines contain functional cancer stem cells with metastatic capacity and a distinct molecular signature. Cancer Res (2009) 69:1302-13. doi:10.1158/0008-5472.CAN-08-2741

26. Bolstad BM, Irizarry RA, Astrand M, Speed TP. A comparison of normalization methods for high density oligonucleotide array data based on variance and bias. Bioinformatics (2003) 19:185-93. doi:10.1093/bioinformatics/19.2.185

27. Smyth GK. Linear models and empirical bayes methods for assessing differential expression in microarray experiments. Stat Appl Genet Mol Biol (2004) 3:Article3. doi:10.2202/1544-6115.1027

28. Benjamini Y, Hochberg Y. Controlling the false discovery rate: a practical and powerful approach to multiple testing. J R Statist Soc B (1995) 57:289-300.

29. Al-Shahrour F, Arbiza L, Dopazo H, Huerta-Cepas J, Mínguez P, Montaner D, et al. From genes to functional classes in the study of biological systems. BMC Bioinformatics (2007) 8:114. doi:10.1186/1471-2105-8-114

30. Medina I, Carbonell J, Pulido L, Madeira SC, Goetz S, Conesa A, et al. Babelomics: an integrative platform for the analysis of transcriptomics, proteomics and genomic data with advanced functional profiling. Nucleic Acids Res (2010) 38:W210-3. doi:10.1093/nar/gkq388

31. Benjamini Y, Yekutieli D. The control of the false discovery rate in multiple testing under dependency. Ann Stat (2001) 29:1165-88. doi:10.1186/14712105-9-114

32. Götz S, García-Gómez JM, Terol J, Williams TD, Nagaraj SH, Nueda MJ, et al. High-throughput functional annotation and data mining with the Blast2GO suite. Nucleic Acids Res (2008) 36:3420-35. doi:10.1093/nar/gkn176

33. Glynn SA, Boersma BJ, Dorsey TH, Yi M, Yfantis HG, Ridnour LA, et al. Increased NOS2 predicts poor survival in estrogen receptor-negative breast cancer patients. J Clin Invest (2010) 120:3843-54. doi:10.1172/JCI42059

34. Singh JK, Simões BM, Clarke RB, Bundred NJ. Targeting IL-8 signalling to inhibit breast cancer stem cell activity. Expert Opin Ther Targets (2013) 17:1235-41. doi:10.1517/14728222.2013.835398

35. Visvader JE, Lindeman GJ. Cancer stem cells: current status and evolving complexities. Cell Stem Cell (2012) 10:717-28. doi:10.1016/j.stem.2012.05.007

36. Ricardo S, Vieira AF, Gerhard R, Leitão D, Pinto R, Cameselle-Teijeiro JF, et al. Breast cancer stem cell markers CD44, CD24 and ALDH1: expression distribution within intrinsic molecular subtype. J Clin Pathol (2011) 64(11):937-46. doi:10.1136/jcp.2011.090456
37. Charafe-Jauffret E, Ginestier C, Bertucci F, Cabaud O, Wicinski J, Finetti P, et al. ALDH1-positive cancer stem cells predict engraftment of primary breast tumors and are governed by a common stem cell program. Cancer Res (2013) 73(24):7290-300. doi:10.1158/0008-5472.CAN-12-4704

38. Levings PP, McGarry SV, Currie TP, Nickerson DM, McClellan S, Ghivizzani SC, et al. Expression of an exogenous human Oct-4 promoter identifies tumor-initiating cells in osteosarcoma. Cancer Res (2009) 69:5648-55. doi:10. 1158/0008-5472.CAN-08-3580

39. Zbinden M, Duquet A, Lorente-Trigos A, Ngwabyt S-N, Borges I, Ruiz i Altaba A. NANOG regulates glioma stem cells and is essential in vivo acting in a cross-functional network with GLI1 and p53. EMBO J (2010) 29:2659-74. doi:10.1038/emboj.2010.137

40. Wu F, Zhang J, Wang P, Ye X, Jung K, Bone KM, et al. Identification of two novel phenotypically distinct breast cancer cell subsets based on Sox 2 transcription activity. Cell Signal (2012) 24:1989-98. doi:10.1016/j.cellsig.2012.07.008

41. Lengerke C, Fehm T, Kurth R, Neubauer H, Scheble V, Muller F, et al. Expression of the embryonic stem cell marker SOX2 in early-stage breast carcinoma. BMC Cancer (2011) 11:42. doi:10.1186/1471-2407-11-42

42. Rodriguez-Pinilla SM, Sarrio D, Moreno-Bueno G, Rodriguez-Gil Y, Martinez MA, Hernandez L, et al. Sox2: a possible driver of the basal-like phenotype in sporadic breast cancer. Mod Pathol (2007) 20:474-81. doi:10.1038/modpathol. 3800760

43. Vazquez-Martin A, Cufí S, López-Bonet E, Corominas-Faja B, Cuyàs E, Vellon L, et al. Reprogramming of non-genomic estrogen signaling by the stemness factor SOX2 enhances the tumor-initiating capacity of breast cancer cells. Cell Cycle (2013) 12:3471-7. doi:10.4161/cc.26692

44. Iliopoulos D, Hirsch HA, Wang G, Struhl K. Inducible formation of breast cancer stem cells and their dynamic equilibrium with non-stem cancer cells via IL6 secretion. Proc Natl Acad Sci U S A (2011) 108:1397-402. doi:10.1073/pnas. 1018898108

45. Wang A, Arantes S, Yan L, Kiguchi K, McArthur MJ, Sahin A, et al. The transcription factor ATF3 acts as an oncogene in mouse mammary tumorigenesis. BMC Cancer (2008) 8:268. doi:10.1186/1471-2407-8-268

46. Yin X, Wolford CC, Chang Y-S, McConoughey SJ, Ramsey SA, Aderem A, et al. ATF3, an adaptive-response gene, enhances TGF $\beta$ signaling and cancerinitiating cell features in breast cancer cells. J Cell Sci (2010) 123:3558-65. doi:10.1242/jcs.064915

47. Mani SA, Guo W, Liao MJ, Eaton EN, Ayyanan A, Zhou AY, et al. The epithelialmesenchymal transition generates cells with properties of stem cells. Cell (2008) 133:704-15. doi:10.1016/j.cell.2008.03.027

48. Morel AP, Lievre M, Thomas C, Hinkal G, Ansieau S, Puisieux A. Generation of breast cancer stem cells through epithelial-mesenchymal transition. PLoS ONE (2008) 3(8):e2888. doi:10.1371/journal.pone.0002888

49. Guo W, Keckesova Z, Donaher JL, Shibue T, Tischler V, Reinhardt F, et al. Slug and Sox 9 cooperatively determine the mammary stem cell state. Cell (2012) 148:1015-28. doi:10.1016/j.cell.2012.02.008

50. Kong C, Wang C, Wang L, Ma M, Niu C, Sun X, et al. NEDD9 is a positive regulator of epithelial-mesenchymal transition and promotes invasion in aggressive breast cancer. PLoS One (2011) 6:e22666. doi:10.1371/journal.pone. 0022666

51. Izumchenko E, Singh MK, Plotnikova OV, Tikhmyanova N, Little JL, Serebriiskii IG, et al. NEDD9 promotes oncogenic signaling in mammary tumor development. Cancer Res (2009) 69:7198-206. doi:10.1158/0008-5472.CAN-09-0795

52. Little JL, Serzhanova V, Izumchenko E, Egleston BL, Parise E, Klein-Szanto AJ, et al. A requirement for Nedd9 in luminal progenitor cells prior to mammary tumorigenesis in MMTV-HER2/ErbB2 mice. Oncogene (2014) 33(4):411-20. doi:10.1038/onc.2012.607

Conflict of Interest Statement: Juan Manuel Iglesias is an employee of the private commercial company Synpromics Ltd. Angel Garcia Martin and Olatz Leis own stock of the private commercial company StemTek Therapeutics. Juan Gumuzio Barrie is an employee of the private commercial company StemTek Therapeutics. The other co-authors declare that the research was conducted in the absence of any commercial or financial relationships that could be construed as a potential conflict of interest.

Received: 30 July 2014; accepted: 17 October 2014; published online: 04 November 2014. 
Citation: Iglesias JM, Leis O, Pérez Ruiz E, Gumuzio Barrie J, Garcia-Garcia F, Aduriz A, Beloqui I, Hernandez-Garcia S, Lopez-Mato MP, Dopazo J, Pandiella A, Menendez $J A$ and Martin AG (2014) The activation of the Sox2 RR2 pluripotency transcriptional reporter in human breast cancer cell lines is dynamic and labels cells with higher tumorigenic potential. Front. Oncol. 4:308. doi: 10.3389/fonc.2014.00308

This article was submitted to Molecular and Cellular Oncology, a section of the journal Frontiers in Oncology.
Copyright (C) 2014 Iglesias, Leis, Pérez Ruiz, Gumuzio Barrie, Garcia-Garcia, Aduriz, Beloqui, Hernandez-Garcia, Lopez-Mato, Dopazo, Pandiella, Menendez and Martin. This is an open-access article distributed under the terms of the Creative Commons Attribution License (CC BY). The use, distribution or reproduction in other forums is permitted, provided the original author(s) or licensor are credited and that the original publication in this journal is cited, in accordance with accepted academic practice. No use, distribution or reproduction is permitted which does not comply with these terms. 